\title{
Trapping Activity of Nematode-Trapping Fungus Arthrobotrys dactyloides on the Presence of Sawdust, Microorganisms, and Nematodes
}

\author{
Sudirman ${ }^{\left.1^{*}\right)}$ and Karwati Zawani ${ }^{2)}$ \\ 1)Plant Pest and Diseases Study Program, Faculty of Agriculture,University of Mataram, Mataram 83125 \\ ${ }^{2)}$ Horticulture Study Program, Faculty of Agriculture, University of Mataram, Mataram 83125 \\ Diterima 13-03-2010 Disetujui 18-02-2011
}

\begin{abstract}
Once biological control agents of nematodes are introduced into soil, they must function in a very complex and dynamic environment. In soil, both nematodes and their antagonists are influenced by other biotic and abiotic factors. However, our knowledge of the effects of these factors in soil is limited. Hence, instead of focusing on the role of individual organisms in controlling nematode pests, this research aimed to determine the effects of sawdust, microorganisms, and nematodes on trapping activity of Arthrobotrys dactyloides. Experiments were conducted with "standard slide test" and "soil microcosm" using soil amended with various concentrations or without sawdust, with the presence or the absence of microorganisms, and with the presence or the absence of nematodes (Caenorhabditis elegans and/or Meloidogyne javanica). The experiments were carried out with completely randomized design and data were analyzed with analysis of variance followed by Tukey's Honestly Significant Different test. Results showed that sawdust did not have direct effect on ring formation and trapping activity of $\boldsymbol{A}$. dactyloides. However, sawdust did have effect on microorganisms and $C$. elegans which then these two factors stimulated ring formation and trapping activity of $\boldsymbol{A}$. dactyloides.
\end{abstract}

Keywords: Arthrobotrys dactyloides, Meloidogyne javanica, microorganisms, sawdust, Trapping activity

\section{INTRODUCTION}

The presence of organic matter in soil is known to affect the predatory behavior of fungal antagonists (Stirling, 1991). It was hypothesized that the addition of organic matter to soil stimulated nematode-trapping fungi and other inactive fungi into saprophytic competition, and because their poor competitive ability, nematode-trapping fungi avoided competition by preying on free-living nematodes (Cooke, 1977). However, there is almost no data in this area specifically for Arthrobotrys dactyloides, a nematode-trapping fungus that traps nematodes with constricting rings (Stirling, 1991). Results of previous study regarding this topic on the addition of organic matter into alginate granules containing $A$. dactyloides showed that sawdust, cassava, and rice husk did not have any significant effects on the growth, ring production and trapping activity of this fungus (Sudirman, 2009).

\footnotetext{
*Telp: +6281936713000

Email: su_dirman@yahoo.com
}

Nevertheless, it was still possible that the addition of specific types of organic matter to soil could stimulate predatory behaviour in $A$. dactyloides. In environments with a high $\mathrm{C} / \mathrm{N}$ ratio, Barron (1992), has hypothesized that nematode-trapping fungi are stimulated to increase trapping because they need to obtain nitrogen from nematodes.

Most studies on organic amendments for nematode control (Lazarovits et al., 1999; Akhtar \& Malik, 2000) have mainly been done with nitrogen-rich amendments such animal manure, meat and bone meal, soy meal, oil cakes and chitin. These organic materials produce nematicidal compounds such as ammonia and nitrous acid at concentrations that are sufficient to kill plantparasitic nematodes when they are applied to soil at application rates of 5-100 t ha $^{-1}$ (Larazovits et al., 1999; Oka \& Yermiyahu, 2002). Nematicidal effects, however, are relatively short-lived because ammonia concentrations remain high for a limited time (Cowling et al., 2001; Oka \& Pivonia, 2002). Hence, instead of its nematicidal effects, the use of organic amendments is expected to control nematode through naturally occurring mechanisms. 
In earlier studies with organic amendments in the sugar industry (Stirling et al., 2003; Pankhurst et al., 2005), various organic materials were added to a sugarcanegrowing soil and results showed that amendments with a high $\mathrm{C} / \mathrm{N}$ ratio induced suppressiveness to Meloidogyne javanica and Pratylenchus zeae 4 and 7 months after they were added to the soil. This suppression of nematodes was reported to be associated with low levels of nitratenitrogen in soil, a fungal-dominant soil biology and high numbers of omnivorous nematodes (Stirling et al., 2003).

Organic matter can also increase the activity of soil microorganisms which cause mycostatic and lytic effects on biological control agents. Stirling and Mani (1995), reported that no traps were produced by Dactylella candida or Arthrobotrys dactyloides in sand that had been amended with horse manure and compost. They suggested that the addition organic matters stimulated mycostatic and lytic effects of other soil microorganisms. Research on the predation of nematophagous fungi on the presence of various numbers of nematodes and levels of organic matter should be carried out. Result of a preliminary study (unpublished data) looking at the growth of $A$. dactyloides in four different types of organic matter showed that this fungus could grow well on organic matters with high carbon content such as; sawdust, corn cob, and rice husk, but it did not on substrate with high nitrogen content like chicken manure.

This study aimed to determine whether the addition of sawdust into soil stimulated the activity of $A$. dactyloides (ring production, trapping activity, and nematode mortality).

\section{MATERIALS AND METHODS}

Preparation of Sterile Second Stage (J2) of Meloidogyne javanica. Meloidogyne javanica cultures were maintained on susceptible tomato plants grown in sandy soil in 1,2 I pots in the glasshouse. Eggs of M. javanica were extracted with sodium hypochlorite method (Hussey \& Barker, 1973). Sterile second stage juveniles (J2) were produced by adding concentrated nematode-egg suspension to $10 \mathrm{ml}$ agar $\left(1 \%, 45-48^{\circ} \mathrm{C}\right)$, mixed well, and poured into the centre of a sterile Petri dish and allowed to solidify. An antibiotic medium was prepared by adding $1.2 \mathrm{ml}$ of streptomycin solution ( $1 \mathrm{~g}$ of streptomycin sulphate in $100 \mathrm{ml}$ sterile distilled water) and $0.0095 \mathrm{~g}$ of methoxy ethyl mercuric chloride to $250 \mathrm{ml}$ of water agar. The antibiotic medium was poured gently over the solidified nematode egg-agar suspension until covered to a depth of $5 \mathrm{~mm}$. The plates were then incubated for 36 hours at $25^{\circ} \mathrm{C}$ to allow $\mathrm{J} 2$ to hatch from eggs and migrate to the agar surface. Juveniles were washed into a sterile beaker using 10 $\mathrm{ml}$ of sterile distilled water.

Preparation of Caenorhabditis elegans. Caenorhabditis elegans was cultured on a lawn of Escherichia coli. The bacterial lawn was prepared by evenly spreading $1 \mathrm{ml}$ of an E. coli suspension on the surface of one-fourth strength nutrient agar (1.5\% agar) in a Petri dish. The Petri dish was incubated at $27^{\circ} \mathrm{C}$ for 5 days and then inoculated with $C$. elegans. When needed, nematodes were then washed from the plate with sterile water.

Preparation of Soil and Sawdust. Soil used in this study was sandy soil ( $28 \%$ coarse sand, $55 \%$ fine sand, $7 \%$ silt and $10 \%$ clay). The soil moisture contents at field capacity and permanent wilting point were 14\% and $10 \%$, respectively. Soil taken from the field was air dried by spreading soil in a shaded area for a few days. The air dried soil was then sieved with a $2 \mathrm{~mm}$-aperture sieve and stored in bins until required. The nematodefree-soil was prepared by heating soil at $70^{\circ} \mathrm{C}$ for about 60 minutes. Sterile soil was prepared by autoclaving moist soil in plastic bags for three consecutive days at $121^{\circ} \mathrm{C}$ for 20 minutes before being used in experiments.

Sterile sawdust was prepared by the same manner with sterile soil. The carbon and nitrogen contents were $90 \%$ and $0.36 \%$, respectively.

The Nematode-Trapping fungus, Arthrobotrys dactyloides, Mass Production of Mycelia and Formulation. The fungus used in this research was Arthrobotrys dactyloides isolate Ampenan. The fungus was grown on corn meal agar (CMA) in $9 \mathrm{~cm}$ diameter Petri dishes. When the whole surface of the dish was covered by mycelia, the agar was cut into squares $(6 \mathrm{~mm} \times 6 \mathrm{~mm})$ and stored in bottles containing sterile distilled water at $27^{\circ} \mathrm{C}$. When fungus was required for experiments, one square from this water culture was placed on CMA in a $9 \mathrm{~cm}$ diameter Petri dish and plates were incubated at $27^{\circ} \mathrm{C}$ for $6-7$ days before use. The fungus was mass produced in $250 \mathrm{ml}$ Ehrlenmeyer flasks containing $100 \mathrm{ml}$ Glucose Peptone yeast (GPY) broth (15 g glucose, $2 \mathrm{~g}$ peptone, $5 \mathrm{~g}$ yeast, $1 \mathrm{~g}$ asparagine, $0.5 \mathrm{~g} \mathrm{~K}_{2} \mathrm{HPO}_{4}, 0.25 \mathrm{~g} \mathrm{MgSO}_{4} .7 \mathrm{H}_{2} \mathrm{O}, 0.001$ $\mathrm{g}$ thiamine $\mathrm{HCl}, 1 \mathrm{~L} \mathrm{H}_{2} \mathrm{O}$ ) (Sudirman, 1997; 2009). Flasks were inoculated with two $5 \mathrm{~mm}$-diameter discs taken from an actively growing colony on CMA as 
described previously and were incubated at $27^{\circ} \mathrm{C}$ on a rotary shaker at $120 \mathrm{rpm}$. After 10 days incubation, about $0.007 \mathrm{~g}$ dry wt biomass $\mathrm{ml}^{-1}$ was produced. Before it was used, the mycelial suspension was homogenized for 15 seconds with blender.

The fungus was formulated into kaolin-alginate granules based on technique developed by Sudirman, (1997; 2009). $100 \mathrm{~g}$ kaolin (MP Biomedical Inc, Ohio, USA) and $10 \mathrm{~g}$ sodium alginate were added to 1 I water. After autoclaving, $80 \mathrm{ml}$ of the blended and sterilized kaolin-alginate mixture was mixed with $20 \mathrm{ml}$ of mycelial suspension prepared as described previously. The mixture was then mixed with a magnetic stirrer in a 11 Ehrlenmeyer flask and dripped through a Pasteur pipette into a continuously shaken aqueous suspension of $0.1 \mathrm{M} \mathrm{Ca-gluconate.} \mathrm{The} \mathrm{drops} \mathrm{gelled} \mathrm{upon} \mathrm{contact}$ with the Ca-gluconate. In order to maintain a homogenous spherical form of granules, the distance between the tip of the Pasteur pipette and the surface of the Ca-gluconate suspension was kept at about 1 $\mathrm{cm}$. Granules were harvested and transferred to Ehrlenmeyer flasks containing $100 \mathrm{ml}$ GPY broth and incubated in shake culture at $27^{\circ} \mathrm{C}$. After 3 days, the re-fermented granules were harvested and dried on a sterile wire mesh. The diameter and weight of a granule were $3 \mathrm{~mm}$ and $3.5 \mathrm{~g}$, respectively.

Effect of Sawdust on Growth and Ring Production in Soil. This experiment aimed to determine the growth of $A$. dactyloides in soil amended with different amounts of sawdust. Six different concentrations $(0.0,0.2,0.4,0.6,0.8$, and $1.0 \% \mathrm{w} / \mathrm{w})$ of sawdust were separately added to sterile soil, moistened with sterile water and incubated for 8 weeks before being used. The growth of $A$. dactyloides from granules in each soil/sawdust mixture was assessed with a standard slide test. One granule containing Arthrobotrys dactyloides was placed at marked positions on a glass slide at the bottom of a $9-\mathrm{cm}$ diameter Petri dish. The granule was covered with a piece of nylon mesh (the same size as the glass slide) with $100 \mathrm{~mm}$ apertures and the Petri dish was then filled with $60 \mathrm{~g}$ of soil, moistened with sterile water to approximately field capacity. The Petri dish was placed in a moist air-tight plastic container (in which humidity was maintained by covering the base and top with 2 layers of moist paper) and incubated at $27^{\circ} \mathrm{C}$. Twenty days later, the soil and nylon mesh were carefully removed so that all granules and mycelia growing from the granules stayed in position. To achieve this, a little pressure was applied with the tip of a fine forceps at the point where a granule was located, and the edge of nylon mesh was lifted in such a way that granules remained in position with minimal disturbance to the mycelia. The mycelia were separated from granules by using a very sharp tip of a forceps to cut around the granules. The granules were then removed. This latter step was done very carefully to avoid mycelia from being disarranged or dislodged with the granules. The slide was then flooded with lactoglycerol cotton blue, a coverslip was applied and the surface of the slide was observed under microscope. Radial growth of mycelia was measured.

To determine the effect of sawdust concentration on ring production, slide test with sterile soil amended with six different concentrations $(0.0,0.2,0.4,0.6,0.8$, and $1.0 \% \mathrm{w} / \mathrm{w}$ ) of sawdust were prepared. Three granules were put on one slide and five replicates for each treatment were prepared and processed as described previously. After 5 days incubation at $27^{\circ} \mathrm{C}$, the number of rings in each slide was observed.

Effect of Sawdust on Trapping activity of $\boldsymbol{A}$. dactyloides. This experiment was conducted in soil microcosms using sterile soil amended and nonamended with $1 \%$ sawdust. For each treatment, 20 microcosms with granules formulated $A$. dactyloides and 20 microcosms without granules formulated $A$. dactyloides were prepared. Microcosms were made from $38 \mathrm{~mm}$ internal diameter PVC pipe. Rings $3 \mathrm{~mm}$ and $6 \mathrm{~mm}$ wide were cut from the pipe and rigid plastic mesh ( $2 \mathrm{~mm}$ diameter pore size) that had been cut to the same external diameter as the pipe was glued between the pipes. Two layers of tissue paper were then placed on the mesh and the larger ring (volume approximately $7 \mathrm{ml}$ ) was filled with $9 \mathrm{~g}$ of soil and packed to a bulk density of approximately 1.3. The soil was then watered to nearly field capacity. Twenty granules were buried in soil and the microcosms were placed in $60 \mathrm{~mm}$ diameter Petri dishes and incubated at $27^{\circ} \mathrm{C}$ in an air-tight plastic container. After 5 days incubation at $27^{\circ} \mathrm{C}$, about 90 freshly hatched $M$. javanica (J2) were inoculated into each of five replicate microcosms of each treatment, and microcosms were re-incubated at $27^{\circ} \mathrm{C}$. After 3 days, the nematodes in each microcosm were extracted by adding water to the Petri dishes to form a 
small Baermann tray. The nematodes that migrated through the tissue in 48 hours at $27^{\circ} \mathrm{C}$ were counted. The inoculation of $M$. javanica was repeated at day 10 , 15 and 20 and nematodes were extracted accordingly.

Effect of Sawdust and Microorganisms on Trapping Activity of $\boldsymbol{A}$. dactyloides. This experiment was carried out with soil microcosms using nematodefree and sterile soil amended with or without sawdust $(1 \% \mathrm{w} / \mathrm{w})$. Before commencing the experiment, the number of propagules of microorganisms in each soil was determined. Forty microcosms (20 with granules and 20 without granules) for each treatment were prepared as described previously. After 5 days incubation at $27^{\circ} \mathrm{C}$, about 90 sterile $M$. javanica were inoculated into each of five replicate microcosms. Three days after inoculation, nematodes were extracted and counted, and the populations of microorganisms were determined by serial dilution method. The inoculation of $M$. javanica was repeated after 10,15 , and 20 days incubation.

Effect of Sawdust, Microorganisms and Caenorhabditis elegans on Ring Production and Trapping Activity of $\boldsymbol{A}$. dactyloides. For ring production, the experiment was conducted with a standard slide test using nematode-free and sterile soil, with and without sawdust, and with and without $C$. elegans. The soil and sawdust was mixed thoroughly, about $500 \mathrm{C}$. elegans were added into each dish and the experiment was set up as described previously, with five replicates for each treatment. After 5 days incubation at $27^{\circ} \mathrm{C}$, the number of rings was counted, the population density of $C$. elegans was determined, and populations of microorganisms were determined by serial dilution method.

For trapping activity, the experiment was carried out with soil microcosms using nematode-free and sterile soil, with or without sawdust, and with or without the presence of $C$. elegans. Sawdust ( $1 \% \mathrm{w} / \mathrm{w})$ was added and mixed thoroughly into the soil. At day 0 , about 90 C. elegans were introduced to the appropriate microcosms. Each treatment was set with 20 microcosms with granules and 20 microcosms without granules, with microcosms being prepared as described previously. After 5 days incubation at $27^{\circ} \mathrm{C}$, about 90 $M$. javanica were inoculated into five replicate microcosms. Three days after inoculation with $M$. javanica, nematodes were extracted and counted. The populations of microorganisms were determined by a serial dilution method. The inoculation of $M$. javanica was repeated for each treatment after incubation for 10,15 , and 20 days.

Statistical Analysis. All experiments were conducted using a completely randomized design with five replicates. The data were analyzed by analysis of variance using GenStat ${ }^{\circledR}$ Discovery $2^{\text {nd }}$ Edition. When the variance ratio $(F)$ was significant, means for each treatment were separated using Tukey's Honestly Significant Difference test. Before analysis data of nematode's mortality were transformed into $\operatorname{arc} \sin \mathrm{dx}$.

\section{RESULTS AND DISCUSSION \\ Effect of Sawdust on Growth and Ring} Production of $\boldsymbol{A}$. dactyloides in Soil. Neither the presence of sawdust nor its concentration had any significant effect on the growth of $A$. dactyloides in soil. The radial growth of mycelia from granules in the extreme treatments ranged from $16.2 \pm 1.64 \mathrm{~mm}$ to $16.4 \pm 1.14 \mathrm{~mm}$. In all treatments, the fungus grew at a growth rate of approximately $0.85 \mathrm{~mm}$ per day. Sawdust did not stimulate ring production. Regardless of the concentration of sawdust used, rings were not observed.

It has been reported that for many species of nematode-trapping fungi, trap formation and trapping activity are conditioned by the nutrient status of the medium, especially the $\mathrm{C} / \mathrm{N}$ ratio (Hayes \& Blackburn, 1966; Nordbring-Hertz, 1968). In this study, however, sawdust with very high $\mathrm{C} / \mathrm{N}$ ratio did not induce ring formation and trapping activity. Sawdust was used to minimize harmful effects of nitrogen on nematodes (Sarathchandra et al., 2001; Tenuta \& Ferris, 2004) in order to conserve or enhance potentially useful biological control agent of nematode, in this case nematode trapping-fungus $A$. dactyloides. A. dactyloides grew on most carbon sources, but did not grow on organic materials with a high $\mathrm{N}$ content (i.e. poultry manure) (unpublished data). This suggests that attempts to enrich soil with carbon sources or the addition of organic amendments with high $\mathrm{C} / \mathrm{N}$ ration will not have a damaging effect on $A$. dactyloides. This conclusion is supported by the observation that $A$. dactyloides grew well in soil amended with various concentrations of sawdust.

Effect of Sawdust on Trapping activity of $\boldsymbol{A}$. dactyloides. Sawdust, incubation time and their 
interaction significantly influenced trapping activity of A. dactyloides. Sawdust did not have any significant effect on mortality of $M$. javanica during the first 10 days (Figure 1). After incubation for 15 days, however, the presence of sawdust significantly increased the mortality of $M$. javanica and this effect became even more apparent by day 20.

It has been demonstrated unequivocally in many reports (Stirling \& Many, 1995; Sudirman, 1997; 2009), that trapping activity is strongly related to ring formation. Sawdust did not have a direct effect on ring formation or on trapping activity, as there was no significant difference in nematode mortality in amended and nonamended soils soon after $A$. dactyloides was added to sterile soil. However, sawdust seemed to serve as food source for $A$. dactyloides, because as the incubation time increased, nematode mortality in sawdustamended soil was constantly higher than in nonamended soil (Figure 1). Barron (1992), suggested that nematode-trapping fungi are adapted to high $\mathrm{C}$, low $\mathrm{N}$ habitats, and appear to trap nematodes to obtain $\mathrm{N}$.

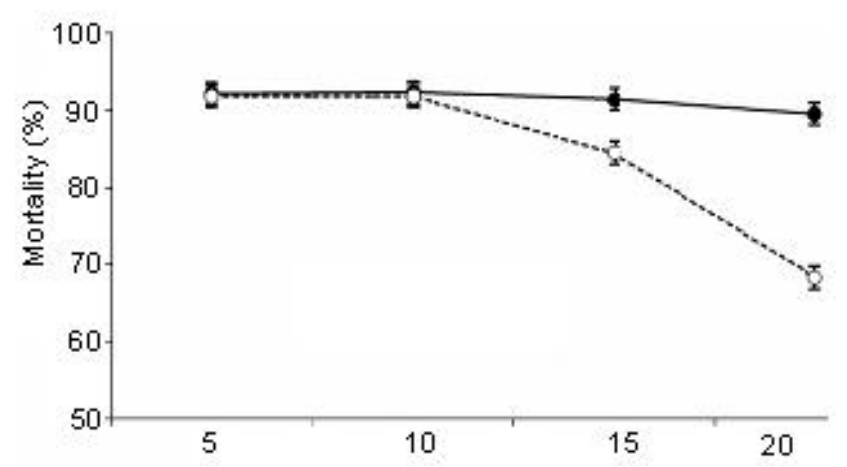

Length of incubation (days) when $M$. javanica was inoculated $\rightarrow$ With savdust $\ldots \infty-\cdots$ Without sandust after introduction of granules containing $A$. dactyloides in sterile soil with and without the addition of sawdust. Bars are values of $\mathrm{HSD}_{0.01}$

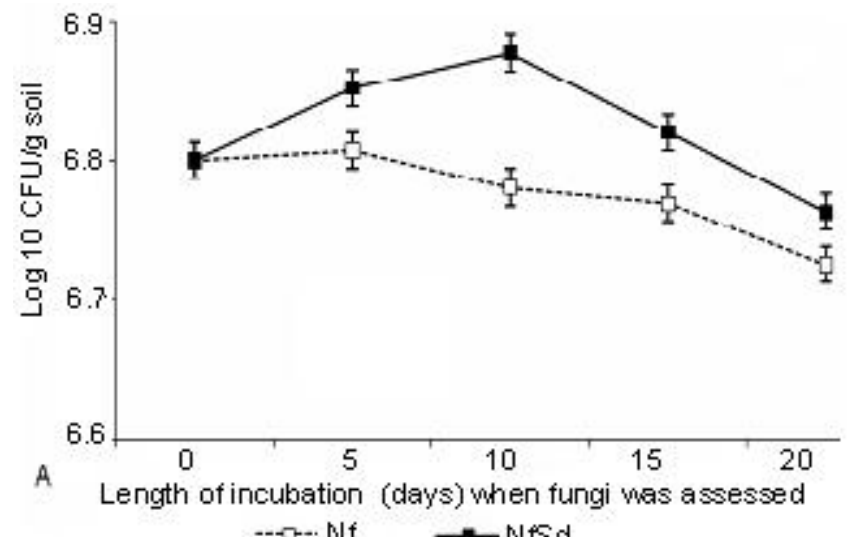

Figure 1. Mortality of $M$. javanica, introduced at various periods

The importance of nematodes in trap formation was demonstrated by Jaffee $(2002 ; 2004)$, who reported that without the presence of nematodes, nematode trappingfungi were never observed to form traps in microcosms containing amended sterile soil. While in non sterile condition, in which Arthrobotrys is supposed to use carbon sources and nematodes as a nitrogen source, is considered a relatively poor competitor (Jaffee, 2003).

Effect of Sawdust and Microorganisms on Trapping Activity of $\boldsymbol{A}$. dactyloides. Sawdust, microorganisms, incubation time, and their interaction significantly influenced trapping activity. The result showed that no significant difference in nematode mortality after introducing $M$. javanica following 5 days inoculation. (Figure 2). As incubation time increased, nematode mortality decreased significantly in microcosms containing sterile or nematode-free soil that was not amended with sawdust. In contrast,

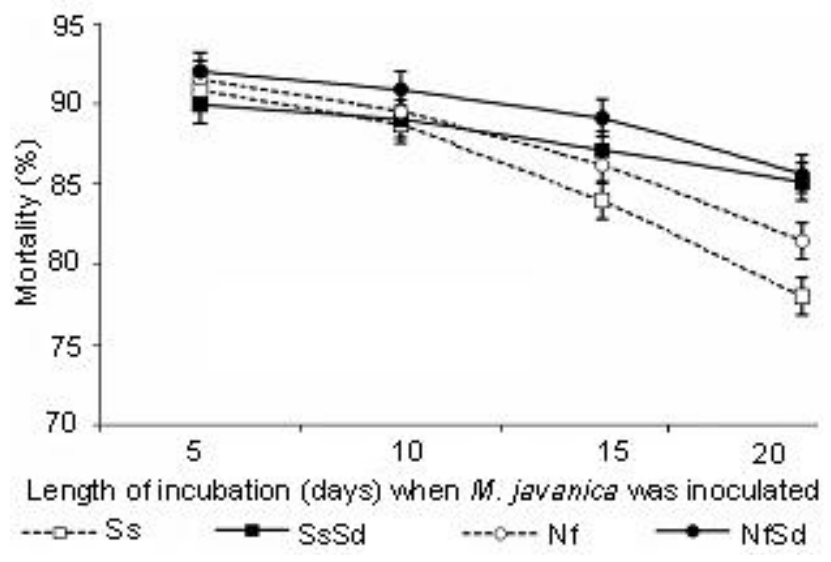

Figure 2. Mortality of $M$. javanica introduced at various periods after the introduction of granules containing $A$. dactyloides in microcosms containing nematode-free and sterile soil amended with or not amended with sawdust. Bars are values of $\mathrm{HSD}_{0.01}$. (Ss = sterile soil, $\mathrm{Nf}=$ Nematode-free soil, $\mathrm{SsSd}=$ Sterile soil amended with sawdust, and NfSd = Nematode-free soil amended with sawdust)

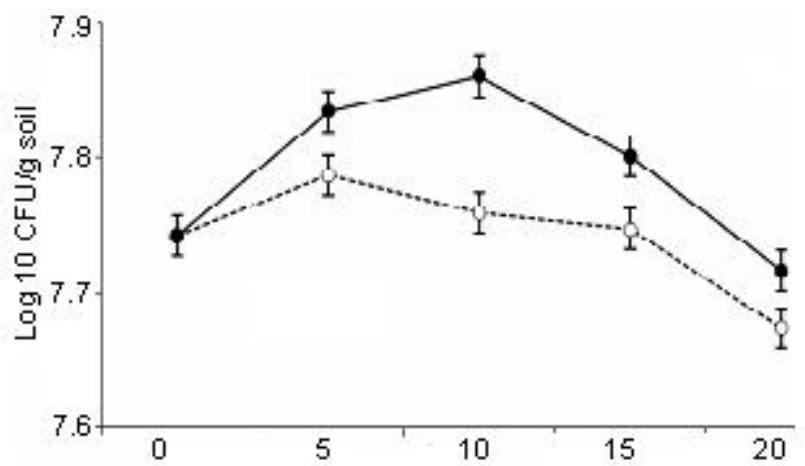

Length of incubation (days) when bacteria mas assessed $\cdots 0 \cdots N f \quad \longrightarrow N f S d$

Figure 3. Populations of fungi (A) and bacteria (B) assessed after various periods of incubation in nematode-free soil with and without sawdust. Bars are values of $\mathrm{HSD}_{0.01}$. ( Nf $=$ nematode-free soil, and $\mathrm{NfSd}=$ nematode-free soil amended with sawdust) 
nematode mortality remained at a high level until day 15 in soil amended with sawdust, and then began to decrease. The addition of sawdust significantly increased the population of both fungi (Figure 3.A) and bacteria (Figure 3.B), especially during the first 10 days. At days 15 and 20, the population of both fungi and bacteria had decreased significantly. Fungal and bacterial populations were higher in soil amended with sawdust than in non-amended soil.

Effect of Sawdust, Microorganisms and Caenorhabditis elegans on Ring Production and Trapping Activity. Sawdust, microorganisms, C. elegans, and their interaction significantly influenced ring formation (Figure 4A). In the absence of microorganisms and $C$. elegans, no rings were formed, regardless of the presence or absence of sawdust. Microorganisms had a slight effect on ring formation, as no rings were formed in sterile soil whereas some rings were produced in nematode-free soil. C. elegans strongly influenced ring formation, as a large number of rings were formed when this nematode was present. Significantly more rings were formed when sawdust, microorganisms, and $C$. elegans were present together compared with when one of these factors was absent.

Sawdust did have an indirect effect on ring formation and trapping activity by influencing microorganisms and
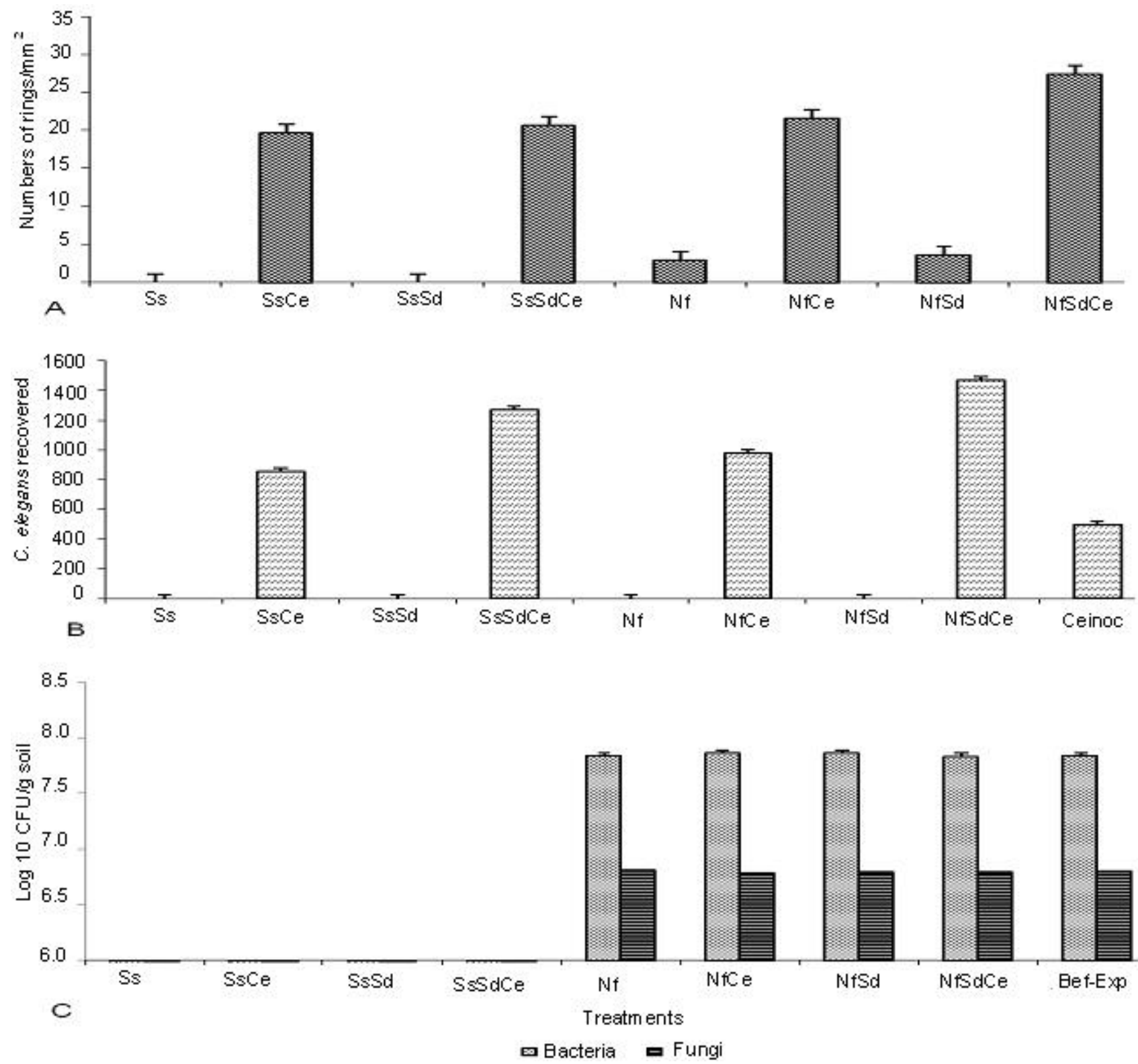

Figure 4. The effect of sawdust, microorganisms and $C$. elegans on the number of rings (A) produced by $A$. dactyloides, number of C. elegans recovered $(B)$, and the population of micro-organisms $(\mathrm{C})$. Bars are values of $\mathrm{HSD}{ }$. $(\mathrm{Nf}=$ nematode-free soil, $\mathrm{NfSd}=$ nematode-free soil with sawdust, $\mathrm{NfCe}=$ nematode-free soil with $C$. elegans, $\mathrm{NfSdCe}=$ nematode-free soil with sawdust and $C$. elegans, $\mathrm{Ss}=$ sterile soil, $\mathrm{SsSd}=$ sterile soil with sawdust, $\mathrm{SsCe}=\mathrm{Sterile}$ soil with $C$. elegans, and $\mathrm{SsSdCe}$ $=$ sterile soil with sawdust and $\mathrm{C}$. elegans, $\mathrm{Ce}$ inoc = numbers of $\mathrm{C}$. elegans inoculated, bef.exp = before experiment) 
free-living nematodes or other soil biota. In non-sterile soil, the addition of sawdust caused populations of bacteria and fungi to increase. These microorganism population increases resulted in an increase in the number of rings. It is suggested that microorganisms may produce substances that stimulated ring formation. The indirect effect of sawdust on ring stimulation was apparent when microorganisms together with $C$. elegans were present in soil. Besides increasing the population of microorganisms, the addition of sawdust also increased populations of $C$. elegans. Since both of these factors can stimulate ring formation, the number of rings produced in soil amended with sawdust was much higher than in soil without sawdust. Conteh et al., (1997), stated that decomposed organic amendments release organic compounds that are readily utilizable by soil microorganisms. It was not surprising, therefore, that population of bacteria and fungi increased in amended soil. Since bacteria and fungi are parts of free-living nematode's food sources, the increase of these microorganisms populations led to the increase of $C$. elegans population during decomposition process.

The presence of microorganisms significantly increased the population of $C$. elegans. This effect became more pronounced when sawdust was added to soil (Figure $4 \mathrm{~B}$ ). The presence of $C$. elegans significantly reduced the population of bacteria (Figure 4.C).

Furthermore, microorganisms, sawdust, $C$. elegans, and their interaction significantly influenced trapping activity. There was a significant interaction between sawdust, microorganisms and $C$. elegans with regards to nematode mortality. This effect became more pronounced as incubation time increased. At day 5, there was significantly higher nematode mortality in soil without $C$. elegans and sawdust than in soil in which C. elegans and/or sawdust were present. As the incubation time increased, however, the mortality of $M$. javanica decreased significantly in soil without $C$. elegans and sawdust (Figure 5).

In sawdust amended sterile soil, the mortality of M. javanica decreased significantly at day 10 . However, when sawdust was present with microorganisms, the mortality of $M$. javanica was relatively constant until day 15 and decreased significantly at day 20 . When $C$. elegans and microorganisms were absent, $M$. javanica mortality decreased slightly until day 15 and then significantly at day 20 . In contrast, when sawdust, microorganisms and $C$. elegans were present, mortality of $M$. javanica remained relatively high for the 20 day observation period. The mortality of $M$. javanica was always higher in sawdust-amended soil than in nonamended soil.

The addition of sawdust significantly increased populations of $C$. elegans when compared to soil without sawdust (Figure 6). In microcosms without granules, the addition of sawdust significantly increased populations of $C$. elegans. This was particularly apparent on day 15 and 20, with $C$. elegans populations being significantly higher when microorganisms were present. In microcosms with granules, the population of $C$. elegans recovered was higher when microorganisms and/or sawdust were not present.

The addition of sawdust and the presence of $C$. elegans significantly influenced the population of microorganisms (Figure 7). The population of bacteria (Figure $7 \mathrm{~A}$ ) and fungi (Figure 7 B) increased significantly in microcosms with sawdust alone. When C. elegans was present, however, the population of bacteria and fungi decreased significantly.

The presence of microorganisms and $C$. elegans in sawdust amended soil, the system became more complicated, as sawdust served as a food source not only for $A$. dactyloides but also for microorganisms and $C$. elegans. In this condition, trapping activity of $A$. dactyloides appeared to decline, particularly if only the mortality of $M$. javanica was measured. There was

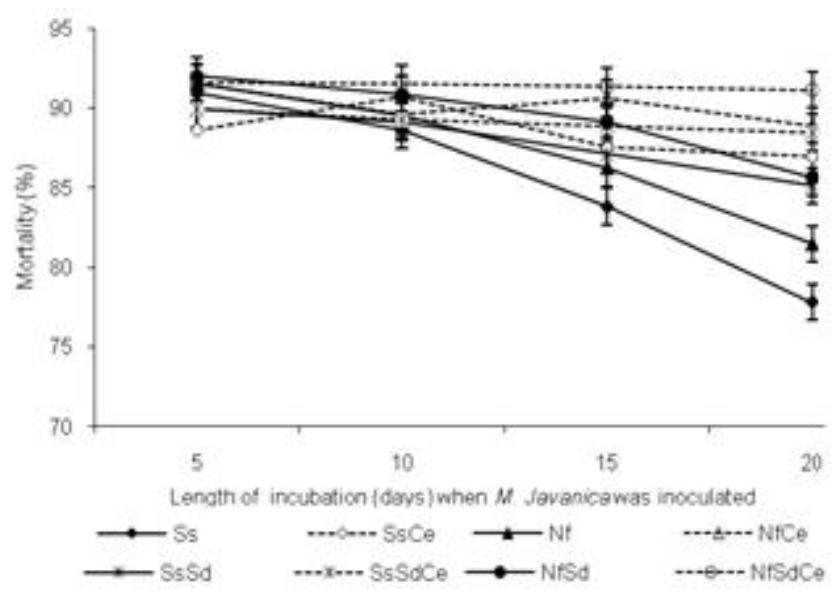

Figure 5. Mortality of $M$. javanica introduced at various periods after introduction of granules containing $A$. dactyloides in microcosms with various treatment combinations. Bars are values of $\mathrm{HSD}_{0.01}$. $\mathrm{Nf}=$ nematode-free soil, $\mathrm{NfSd}=$ nematode-free soil with sawdust, $\mathrm{NfCe}=$ nematode-free soil with $C$. elegans, $\mathrm{NfSdCe}=$ nematode-free soil with sawdust and $C$. elegans, Ss $=$ sterile soil, $\mathrm{SsSd}=$ sterile soil with sawdust, $\mathrm{SsCe}=$ Sterile soil with $C$. elegans, and $\mathrm{SsSdCe}=$ sterile soil with sawdust and $C$. elegans 
higher mortality of $M$. javanica in soil without sawdust and $C$. elegans than in soil amended with sawdust and inoculated with $C$. elegans. However, if the total mortality of nematodes ( $M$. javanica plus $C$. elegans) is considered, the trapping activity of $A$. dactyloides in soil amended with sawdust (in the presence of microorganisms and $C$. elegans), was much higher than in non-amended soil. This indicates that the addition of sawdust caused an increase in population of both bacteria and fungi, and an increase in population of $C$. elegans (observed from microcosms without granules). The population and the activity of $A$. dactyloides probably increased, either to escape increasing competition from other soil saprophytes or in response to the increase in the population of $C$. elegans.

The role of sawdust in influencing biological activity in soil microcosms became more apparent as the time of incubation or the length of observation increased. In soil without sawdust, the population of microorganisms and $C$. elegans decreased significantly over time, whereas in soil with sawdust, the population of both microorganisms and $C$. elegans increased at day 5 and remained high until the end of the experiment (20 days). Populations of $C$. elegans recovered from microcosms with granules were constantly low during the experiment, suggesting that the addition of sawdust did not have any significant effect on populations of $C$. elegans. However, when compared with the populations of $C$. elegans recovered from microcosms without granules, it was clear that the addition of sawdust significantly increased the populations of $C$. elegans. The differences in the number of $C$. elegans recovered from microcosms with and without granules indicate that $A$. dactyloides used $C$. elegans as one of its food sources. As a result of this continually available food source (i.e. C. elegans), A. dactyloides survived and remained active and effective in controlling plant parasitic nematodes (i.e. inoculated $M$. javanica) for a much longer period.

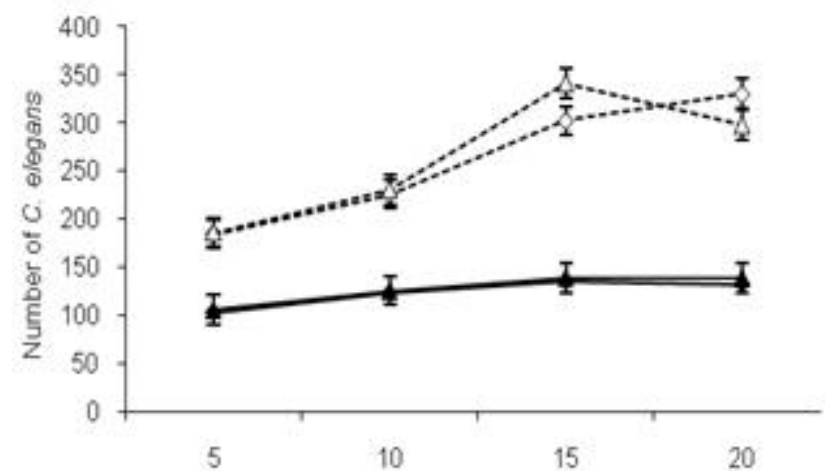

A Length of incubation (days) when $\mathrm{C}$. eleqans was extracted

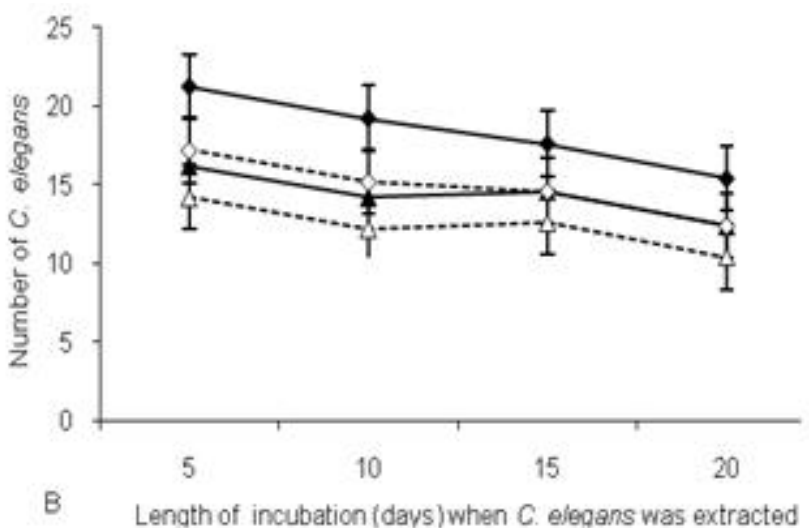

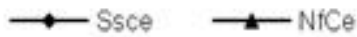

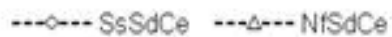

$\longrightarrow$ Ssce

Figure 6. Number of $C$. elegans recovered after various periods of incubation in microcosms treated with various treatments. A) without granules and $\mathrm{B}$ ) with granules. Bars are values of $\mathrm{HSD}_{0.01}$. $\mathrm{SsCe}=$ sterile soil with $C$. elegans, $\mathrm{NfCe}=$ nematodefree soil with $C$. elegans, SsSdCe = sterile soil amended with sawdust and $C$. elegans, and NfSdCe = nematode-free soil amended with sawdust and $C$. elegans
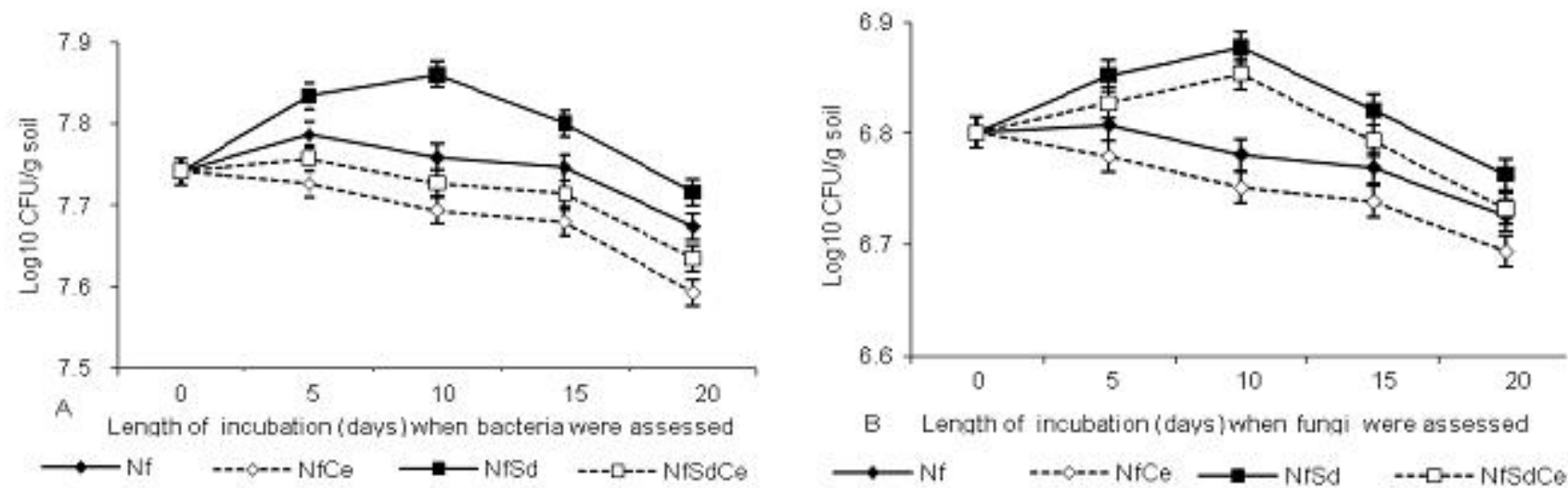

Figure 7. The population of bacteria (A) and fungi $(B)$ after various incubation periods in microcosms with variou's treatments. Bars are values of $\mathrm{LSD}_{0.01}$. $\mathrm{Nf}=$ nematode-free soil, $\mathrm{NfCe}=$ nematode-free soil with $C$. elegans, NfSd = nematode-free soil amended with sawdust, and $\mathrm{NfSdCe}=$ nematode-free soil amended with sawdust and $C$. elegans 


\section{CONCLUSION}

Sawdust had no direct effect on ring formation by A. dactyloides, but it prolonged survival of the fungus in soil. Sawdust served as a food source for $A$. dactyloides, microorganisms, and $C$. elegans. Sawdust improved population of microorganisms and $C$. elegans which then significantly stimulated ring formation and trapping activity of $A$. dactyloides.

\section{AKNOWLEDGEMENT}

This paper was part of a competitive grant research supported by Directorate General of Higher Education, Department of National Education No: 312/SP2H/PP/ DP2M/VI/2009, dated June 16, 2009. The author would like to sincerely thank to Faculty of Agriculture, University of Mataram for all facilities provided to complete the research.

\section{REFERENCES}

Akhtar, M. \& Malik, A. 2000. Roles of organic soil amendments and soil organisms in the biological control of plant-parasitic nematodes. Bioresource Technology 74: 35-47.

Barron, G.L. 1992. Lignolitic and cellulolitic fungi as predators and parasites. In: Carrol, G.C. \& Wicklow, D.T. (eds). The Fungal Community. Its Organization and Role in the Ecosystem. New York: Marcel Dekker Inc.

Conteh, A., Lefroy, R.D.B. \& Blair, G.J. 1997. Dynamic of organic matter in soil as determined by variations in ${ }^{13} \mathrm{C} /{ }^{12} \mathrm{C}$ isotopic ratios and fractionation by ease of oxidation. Australian Journal of Soil Research 35: 881-890.

Cooke, R.C. 1977. The Biology of Symbiotic Fungi. London: Wiley \& Sons.

Cowling, E., Galloway, J., Furines, C., Barber, M. \& Bresser, T. 2001. Optimizing nitrogen management in food and energy production and environmental protection. Proceeding of the $2^{\text {nd }}$ International Nitrogen Conference on Science and Policy. Potomac, Maryland, USA. October 14-18, 2001.

Hayes, W.A. \& Blackburn, F. 1966. Studies on the nutrition of Arthrobotrys oligospora Fres. and $A$. robusta Dudd. II. The predacious phase. Annal Applied Biology 58: 51-60.

Hussey, R.S. \& Barker, K.R. 1973. A comparison of methods of collecting inocula for Meloidogyne spp. including a new technique. Plant Disiese Reporter 57: 1025-1028.
Jaffee, B.A. 2002. Soil cages for studying how organic amendments affect nematode-trapping fungi. Applied Soil Ecology 21: 1-9.

Jaffee, B.A. 2003. Correlations between most probable number and activity of nematode-trapping fungi. Phytopathology 93: 1599-1605.

Jaffee, B.A. 2004. Do organic amendments enhance the nematode-trapping fungi Dactylellina haptotyla and Arthrobotrys oligospora? Journal of Nematology 36: 267275.

Larazovits, G., Conn, K.L. \& Potter, J. 1999. Reduction of potato scab, verticillium wilt, and nematodes by soymeal and meat and bone meat in two Ontario potato fields. Canadian Journal of Plant Pathology 21: 345-353.

Nordbring-Hertz, B. 1968. The influence of medium composition and additions of animal origin on the formation of capture organ in Arthrobotrys oligospora. Physiologia Plantarum 21: 52-65.

Oka, Y. \& Pivonia, S. 2002. Use of ammonia-releasing compounds for control of the root-knot nematode Meloidogyne javanica. Nematology 4: 65-71.

Oka, Y. \& Yermiyahu, U. 2002. Suppressive effects of composts against the root-knot nematode Meloidogyne javanica on tomato. Nematology 4: 91-98.

Pankhurst, C.E., Blair, B.L., Magarey, R.C., Stirling, G.R., Bell, M.J. \& Garside, A.L. 2005. Effect of rotation breaks and organic matter amendments on the capacity of soils to develop biological suppression towards soil organisms associated with yield decline of sugarcane. Applied Soil Ecology 28: 271-282.

Sarathchandra, S.U., Ghani, A., Yeates, G.W., Burch, G. \& Cox, N.R. 2001. Effect of nitrogen and phosphate fertilizers on microbial and nematode diversity in pasture soils. Soil Biology and Biochemistry 33: 953-964.

Stirling, G.R. 1991. Biological Control of Plant Parasitic Nematodes. Wallingford, Oxon: CAB International.

Stirling, G.R. \& Mani, A. 1995. The activity of nematode-trapping fungi following their encapsulation in alginate. Nematologica 41: $240-250$.

Stirling, G.R., Wilson, E.J., Stirling, A.M., Pankhurst, C.E., Moody, P.W. \& Bell, M.J. 2003. Organic amendments enhance biological suppression of plant parasitic nematodes in sugarcane soils. Australian Society of Sugar Cane Technologists 25: 6271.

Sudirman. 1997. Nematophagous activity of Arthrobotrys dactyloides once encapsulated into kaolin alginate granules and introduced into soil. Ph,D. Dissertation. Brisbane: The University of Queensland.

Sudirman. 2009. Improving formulation of Arthrobotrys dactyloides, a nematode-trapping fungus, in kaolin-alginate granules. Crop Agro 2(1): 51-59.

Tenuta, M. \& Ferris, H. 2004. Sensitivity of nematode life-history groups to ions and osmotic tensions of nitrogenous solutions. Journal of Nematology 36: 85-94. 